\title{
Chapter 13 \\ Associations Between Lone Motherhood and Depression: A Co-twin Control Study
}

\author{
Diana Dinescu, Megan Haney-Claus, Eric Turkheimer, and Robert E. Emery
}

\section{Introduction}

Both in Europe and in the United States, lone mothers receive more condemnation than sympathy from the media, politicians, and even religious figures. Lone mothers are blamed for their children's bad grades, for poverty, and even for gun violence. This makes it all the more important to understand the effect that their parenthood status has on their mental health and well being. Research shows that women are more likely to be depressed than men, controlling for age, education, and employment (Atkins 2010; Collings et al. 2014), and lone mothers' risk increases three fold compared to married mothers (Cairney and Wade 2002; Collings et al. 2014). Although in recent decades policy measures have begun to be put in place with the intention to support lone mothers and alleviate their struggles, both Europe, and especially the US, have farther to go.

This chapter will blend research and policy reviews with quasi-experimental results in order to provide more insight into the relationship between lone motherhood and depression. While we will begin by reviewing research that examines lone motherhood using traditional methods, these methods do not fully explain the association between lone motherhood and mental health outcomes such as depression. Thus, we will introduce a useful approach for studying behavioral data, and one that has never been used in the study of lone motherhood: twin research. We will explain its theoretical underpinnings and its practical applications in the matter that is of interest to us: lone motherhood. We will then introduce the case study we will use to illustrate this method. Due to Sweden's generous policies aimed at lone parents,

D. Dinescu $(\varangle) \bullet$ E. Turkheimer $\bullet$ R.E. Emery

University of Virginia, Charlottesville, VA, USA

e-mail: dd7kc@ virginia.edu

M. Haney-Claus

College of William and Mary, Williamsburg, VA, USA

(C) The Author(s) 2018

L. Bernardi, D. Mortelmans (eds.), Lone Parenthood in the Life Course, Life

Course Research and Social Policies 8, DOI 10.1007/978-3-319-63295-7_13 
we will use a Swedish twin sample to investigate the relationship between lone motherhood and depression levels. We will present our methods and results, and discuss our conclusions. Based on our results and the current policies in Sweden, we will discuss implications and possible future directions.

\section{Prior Research Investigating Lone Motherhood and Depression}

Research conducted by teams all over the world (Europe, Canada, the United States, Australia) suggests that lone mothers have a higher risk of depression than married mothers (Cairney et al. 2003; Colton et al. 2015; Crosier et al. 2007; Robinson et al. 2014; Sperlich et al. 2011a; Wang 2004). Women have been found to have an almost doubled risk of depression when compared to men (Atkins 2010), and lone mothers are three times more predisposed to poor health and depression than their married counterparts (Cairney et al. 2004; Colton et al. 2015). Age and race are correlates of this association, with younger women being more predisposed to depression than their older counterparts, (Brown et al. 2012; Horwitz et al. 2007), and lone mothers of color having a higher risk of depression than white mothers (Wang 2004). The number of children is an important predictor of maternal mental health, with more children corresponding with an increase in risk for depression (Horwitz et al. 2007; Sperlich et al. 2011b). Additionally, the amount of social and partner support the mother perceives to have, and chronic stress were also associated with increased risk (Cairney et al. 2003; Sperlich et al. 2011b).

Demographics cannot account fully for this association. Economic hardships were found to be more common in lone-parent families and the resulting strain was associated with an increased vulnerability to depression (Cooper et al. 2008; Crosier et al. 2007). This is explained by considering the resources that better financial status can provide, and that can enhance health and well being: better housing, better nutrition, and better access to health services (Colton et al. 2015). Employment status is an important factor for financial stability: the depression risk of unemployed women is $27 \%$ higher than for employed women, and conversely if the women are employed full time the risk is $29 \%$ lower (Zabkiewicz 2010). In fact, maximum health benefits related to labor come from employment that is full-time, stable, and long term (Evenson and Simon 2005; Wang 2004; Zabkiewicz 2010). However, the picture is more complex when considering mothers.

A full-time job leads to a higher income which is beneficial to lone mothers' mental health (Evenson and Simon 2005), and staying employed can decrease their risk of depression by about 3\% a month (Zabkiewicz 2010). On the other hand, there is evidence that full-time employment may have a negative impact on health, while part time or no employment has a beneficial health effect, when adding children into the analyses (Hewitt et al. 2006). Findings on unemployment are also inconclusive: while some studies found that unemployed lone mothers had 
particularly poor health (Fritzell 2011), other studies, when comparing different policy regimes, found only a marginal direct effect on lone mothers' excess risk of poor health, but did describe a synergy effect between lone motherhood and unemployment (Fritzell et al. 2012). However, it is possible that these differences were due to studies being conducted in different countries with different policy measures aimed at supporting lone mothers. We consider the research on policy regime differences below.

Welfare regime theory is increasingly used in research on the associations between social determinants and health outcomes. This theory argues that population health should be better in social democratic regimes, or in our case that supportive policy measures would help alleviate lone mothers' financial strain - and through it, the risk for depression. However, research is inconclusive as to whether different policy regimes have an impact on the association between lone motherhood and mental health outcomes. Some studies find that lone mothers have significantly worse health than coupled mothers regardless of policy regimes when comparing Italy, Sweden, and Britain (Burstrom et al. 2010), or more generally, that the type of welfare regime does not have a significant impact on health disparities in the population (Brennenstuhl et al. 2012). Other studies reveal more of a struggle to meet basic needs in countries with less support, such as Russia and the US, compared to countries with more support, such as Norway (Brown 2008), and find that lone mothers are at higher risk for depressive feelings in the Bismarckian welfare regime, out of a sample of 27 European countries (Van de Velde et al. 2014). More research is needed in order to understand the complex ways in which policy regimes impact the relationship between lone motherhood and mental health outcomes.

\section{Social Selection vs Social Causation}

Early models of health emphasized biological influences, but scholars now recognize that social factors are an equally important influence on health outcomes (Carr and Springer 2010). Within these, social selection and social causation emerge as dominant alternative explanations proposed for the associations between marriage and better health outcomes (Beam et al. 2011; Emery et al. 2012; Horn et al. 2013), socioeconomic status and psychiatric disorders (Johnson et al. 1999), social class and depression (Ritsher et al. 2001), and in many other such investigations. Researchers continue to debate the extent to which social causation or social selection processes are at play in observed associations between social determinants and health outcomes. We are proposing a study of lone motherhood and depression which uses a special type of data that will help answer the question of whether selection or causation mechanisms are at play in an observer association between our variables of interest.

In the debate between social selection and social causation, the problem arises in trying to tease out correlation from causation. Saying that lone motherhood causes depression is inaccurate if all we have to go on is correlational research. There are 
two possible mechanisms for processes that could explain the relationship between lone parenthood and any kind of psychological outcome: selection and causation. Selection implies that people with positive traits or who exhibit behaviors influenced by their early rearing environments or genotypes tend to select into partnered parenthood (we will use the term "partnered" instead of "married" because we want to account for mothers who choose to be in committed long term relationships without getting married), whereas individuals with more negative traits are at a higher risk of remaining single or getting divorced. Causal pathways imply that intrinsic aspects of partnered parenthood are protective to those who enter into the parenthood state, through mechanisms such as economic advantage, the normative aspect of a relationship, and increased emotional and social support (Emery et al. 2012; Turkheimer and Harden 2013).

In other words, it is possible that depression preceded lone motherhood, or contributed to it. Alternatively, there could be extraneous factors that influence both, such as race, education, socioeconomic status, or upbringing. For instance, growing up in a lone parent home may be more likely to lead someone to become both depressed and a lone mother. People do in fact non-randomly self-select into marital statuses based on their parental marital status, race, and their own mental well-being (Hope et al. 1999; Mastekaasa 1991). Research has also found non-random genetic selection into phenotypes (i.e. observable characteristics) such as divorce (Johnson and $\mathrm{Wu}$ 2001; Simon 2002). An additional concern is that of potential geneenvironment correlation. Someone's genetic makeup is correlated with their environmental experiences, creating a potential extraneous factor that could explain the correlation between, for instance, lone motherhood and depression. In the absence of random assignment, causal inferences are difficult to accomplish. Lone mothers differ from partnered mothers in many ways, some measurable and others impossible to measure. The genetic and environmental selection factors explained above may account for an observed association between, for example, lone motherhood and psychological well-being indicators. Twin research is a robust tool that allows us to account for the presence of possible selection factors and perform a quasiexperimental analysis of correlation and causation. This method has been used extensively in investigations of observed social and behavioral outcomes, from marriage and family research (Beam et al. 2011; Emery et al. 2012; Horn et al. 2013) to BMI and alcohol use (Dinescu et al. 2015; Kaprio 2015).

\section{The Utility of Twin Research in the Study of Behavioral Data}

To the extent that lone motherhood causes differences in depression levels, when we look at twin pairs we should observe this relationship within pairs (i.e. between the two twins in a pair) as well as between them (i.e. comparing one twin pair to another). Within pairs of identical (i.e. monozygotic, or MZ) twins who differ in "motherhood status" (i.e. lone vs. partnered mothers), a causal hypothesis implies that the partnered member of the pair will display different depression levels than 
the lone twin (Turkheimer and Harden 2013). This might be because partnered mothers have more opportunities to take breaks from the stress of parenting, or because they get more emotional support from their partner, or simply because they get to share the burden of parenting and responsibility with someone else. An association between lone motherhood and depression within pairs of MZ twins controls for selection factors arising in either genotype or rearing environment, because the twins are genetically identical and were raised in the same home. In contrast, if the association between lone motherhood and depression is the result of non-causal genetic or environmental confounds, the association would be observed between pairs (families in which mothers tend to be partnered tend to have positive outcomes) but not within them (Turkheimer and Harden 2013). Associations within twin pairs do not conclusively prove causation, because without randomization it is ultimately not possible to control all potential confounds, but because twinships control for genetic and shared environmental confounds at the level of families, they are a step closer than non-genetic research to a causal interpretation of the results (Turkheimer and Harden 2013). We prefer the term quasi-causal to refer to an association between uncontrolled variables that survives testing with a quasiexperimental design in which genetic and shared environmental confounds are controlled.

The utility of twin research can be illustrated by considering the case study of a pair of MZ twins discordant for parenthood status, i.e., one twin is a lone mother and the other one is a partnered mother. Let's imagine that the lone mother also reports significantly higher depression levels than her co-twin. This difference could not be caused by genetic differences, because MZ twins are by definition genetically identical. Moreover, identical twins share many measured and unmeasured environmental experiences such as cultural background, religious upbringing, and family rearing environment; thus differences in depression also cannot be attributed to shared-environmental confounds. Any difference that we observe between the lone mother and her partnered co-twin in our case study must be attributable to the non-shared environmental differences between them. In our case, that is parenthood status, which is the basis on which they were selected. Generalizing from this illustration, we conclude that twin studies offer a quasi-experimental test of whether the relationship between parenthood status and depression is the result of selection or causation.

The advantage of studying twins can be made even clearer by illustrating it graphically. Figure 13.1 presents the difference in selection confounds controlled in analyses involving unrelated adults (no control for genetic or shared environmental confounds), siblings (they share $50 \%$ of their genes, on average, and grow up in the same family at different times), DZ twins (they share $50 \%$ of their genes on average, and are reared together simultaneously), and MZ twins (they share $100 \%$ of their genes and are reared together simultaneously). Selection effects are increasingly evident with each successive comparison; in other words, the difference in depression levels between lone and partnered mothers becomes smaller. The results are not always straightforward: it is possible to encounter various outcomes, based on the selection effects that might be involved. If there is evidence of genetic selection, we 


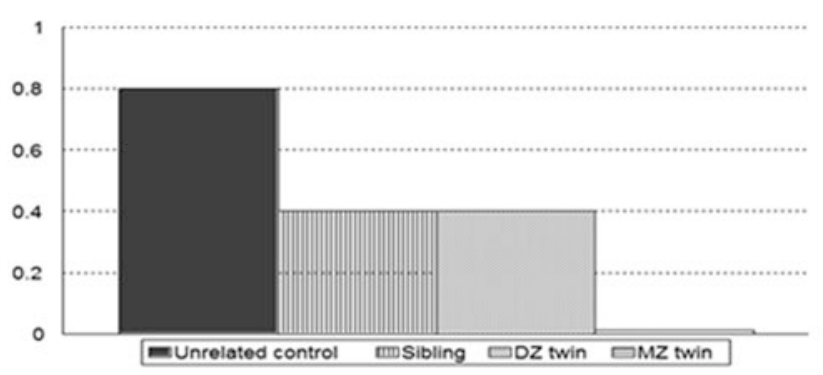

a) Genetic selection effect

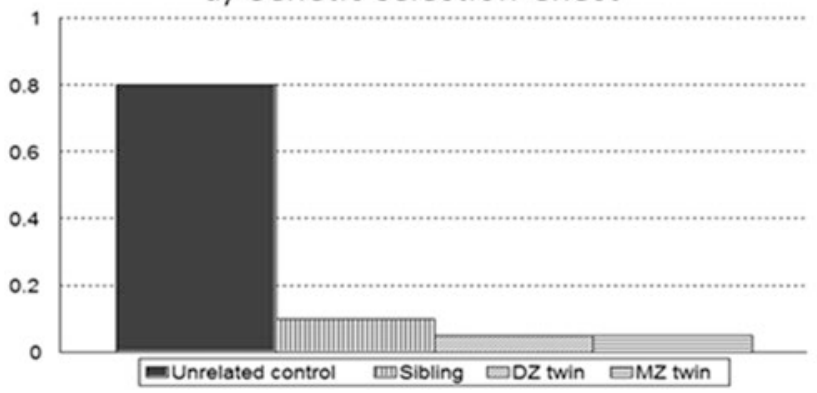

b) Shared environment selection effect

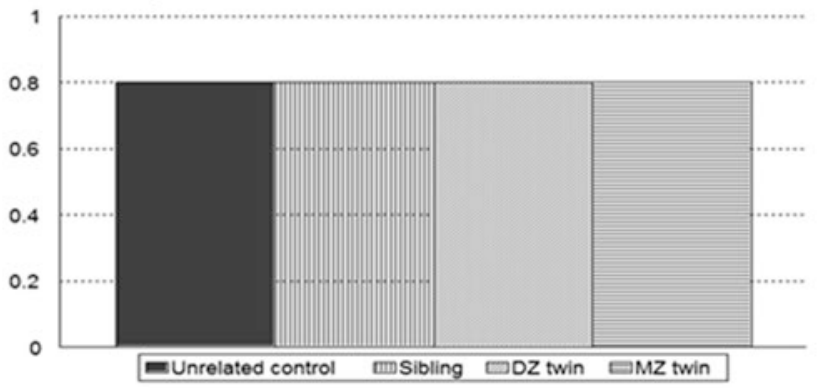

c) No selection effect

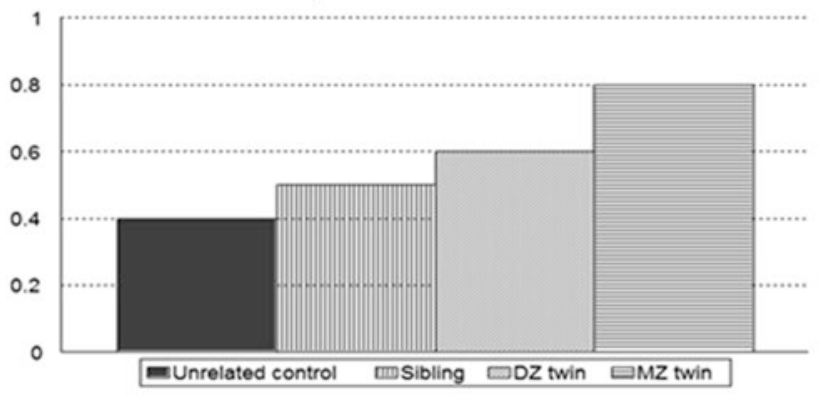

d) Suppression effect

Fig. 13.1 The illustration and interpretation of differences in selection effects obtained by studying unrelated individuals, siblings, and twins 
will notice a $50 \%$ decrease in effect sizes for siblings and DZ twins, and a further decrease to 0 for MZ twins (Fig. 13.1a). If the differences are accounted for by shared environmental selection, the effects will be small for siblings, and will disappear in DZ and MZ twin analyses (Fig. 13.1b). If there are no significant genetic or shared environmental selection confounds, the effect sizes should not differ between the groups (Fig. 13.1c). Lastly, a suppression effect could mask an effect that does in fact exist. What this means is that if lone motherhood did negatively impact women's depression levels, this effect would not be apparent if women who were at low risk for depression also tended to select themselves out of partnered parenthood. If this were the case, the effect sizes would be larger when examining siblings and twins. The magnitude of effect size differences would depend on whether the selection effects were genetically- or environmentally-based, or both (Fig. 13.1d).

We turn to a specific case study using this approach, both to illustrate the power of genetically informed data analysis, and to discuss specific findings. We pose the question: is the relationship between lone motherhood and depression accounted for by non-random selection into lone motherhood, causal consequences of this parenthood status, or both? To that end, we will use the example of Sweden, a country with generous policies aimed to support lone mothers.

\section{Sweden: Current Policy Landscape}

Even among the wealthiest countries in the world there are significant differences between family policies, and between the various levels of support lone mothers receive. The goal of the significantly helpful policies found in Sweden is quite clear: everything revolves around creating a gender-equal economy and protecting the livelihood of children. In countries with progressive family policies, the laws are meant to encourage employment rates in women (regardless of marital or family status), and foster a more equal caretaking responsibility between women and men.

Sweden has three major policies that target family economic security, gender equality, voluntary parenthood, and children's rights (Haas 1996). Sweden supplies allowances for each child, has an extremely generous parental leave policy after the birth of a child, and has a free public childcare program. These policies are universal, and all families are guaranteed certain rights (Haas 1996). These programs do not depend on the income of the child's parents, nor are they short-term or temporary. The creation of these policies is meant to encourage all parents to take on the dual roles of working and child-rearing, with the idea that the laws in place should prevent as many difficulties that might arise from that duality as possible. The laws aim for a horizontal equality among families, regardless of family structure (i.e. lone parent families headed by lone mothers or fathers), number of children, racial or socioeconomic background (Ozawa 2004).

In order to gain this horizontal equality, Sweden's laws aim to keep as many families as possible above the poverty line. This is especially crucial when talking about lone mothers. Oftentimes lone mothers must provide all care-giving and 
economic support for their children. In countries without good family policies, many lone mothers are forced to only work part time in order to care for their child due to high childcare prices. When adequate government policies are not in place to offer support, lone mothers are at a greater risk for poverty (Brady 2006; Misra et al. 2007b). In Sweden, however, lone mothers have less than a 2\% risk of poverty. This statistic is quite impressive when considering that lone mothers in the United States have a risk of over 35\% (Misra et al. 2007a).

Sweden's success in assisting parents, lone mothers in particular, comes from a few key policies. The first of such policies is the child allowance policy. The benefit, as of March 2014, is split equally between the child's guardians if the child is under joint custody, while lone parents get the whole allowance of about \$150 USD per month until the child turns 16 (Nordic Social Insurance Portal-Family Benefits n.d.). This policy displays gender equality as well as the encouragement for women's economic independence, even when in a heterosexual cohabitation. Research has found that when governments give families this type of assistance, poverty is more easily eradicated (Christopher et al. 2002; Christopher 2002; Kenworthy 1999; Misra et al. 2007a; Smeeding 2005).

A second important policy is the parental leave policy that is in place after the birth of a child. A substantial leave policy has been shown to help all mothers, but lone mothers benefit more. In fact, a moderate to strongly generous leave brings lone mothers down to an almost equal risk for poverty as partnered mothers (Misra et al. 2012). Parents share a maximum of 480 days of parental leave, with 2 months exclusively for each parent in order to encourage fathers to spend more time at home with their child. The first 390 days are compensated based on income. If the parent has a low income or no income at all, a basic flat rate is paid. The other 90 days are paid a low flat rate. Altogether, parents are eligible to receive up to $80 \%$ of their income while on leave (Wells and Bergnehr 2014). Leave is designed to allow women to have children, but still keep their competitive and higher paid jobs. $81 \%$ of mothers with children under the age of 18 are employed (Barnombudsmannen 2010), and Sweden's wage gap is lower than the OECD average (OECD n.d.).

Swedish subsidized childcare also keeps women from having to choose between having a child and having economic stability. It has been shown that universal childcare helps to increase both women's participation in the labor market as well as women's wages (Pettit and Hook 2005). As a matter of fact, one of the greatest deterrents that prevent lone mothers from going back to work is lack of affordable childcare (Burstrom et al. 2010). One study showed that childcare provided for children of ages 0-2 was significant in helping reduce the risk of poverty in lone mothers. But in countries where private childcare is the main source of care, despite having many working mothers, the level of poverty is still quite high (Misra et al. 2012). Thus, Sweden's policy is a dual investment; by supplementing childcare, mothers do not have to cut back to a part-time job, and children start out in a stimulating, safe, and educational environment.

We have chosen Sweden as our case study due to the generosity of the policies outlined above. The supportive policy measures in this country create a more equal environment, thus possibly limiting the environmental variability that could affect 
our variables. A twin sample from Sweden would thus offer the potential for limited environmental variability in addition to the possibility of controlling for genetic and shared environmental confounds. Such an investigation will help us distinguish between selection and causation and will bring us a step closer to understanding the mechanisms behind the association between lone motherhood and depression. Below we describe the methods and results of our study.

\section{A Data Illustration Using the Swedish Twin Registry}

\section{Methods}

Data for the current study was drawn from the Swedish Twin Registry (STR), the largest twin registry in the world. The STR contains information from 170,000 Swedish twins born since 1886 . Several birth cohorts make up the registry totaling 29,030 MZ male twin pairs, 27,372 MZ female twin pairs, and 28,686 DZ twin pairs. Data were collected through online, telephone, and mailed questionnaires, and gathered information regarding diseases with a focus on exposure during young adulthood and midlife. We analyzed data from a cohort of the Swedish Twin Registry (STR), the Swedish Twin study of Adults: Genes and Environment (STAGE). This cohort included twins born between 1959 and 1985. The information collected included history pertaining to physical and emotional health, work history, family composition, alcohol and tobacco habits, and major life events. Of the 42,582 eligible twins, 59.6\% responded $(\mathrm{N}=25,364)$. Data for this study came from 1316 twin pairs (738 MZ; $578 \mathrm{DZ}$ ), and response rates for all variables were 90-95\% in our sample.

For the purposes of the current analysis, we focus only on parental status, depression score, education level, and number of children. Parental status was determined based on a measure of marital status (from a self report item we selected the answers married and cohabitating to make up the "partnered" group, and divorced, separated, and living alone for the "lone" group) plus a measure of number of children. Of the members of these "lone" and "partnered" groups, we kept those participants who were living with one or more biological children at the time of the survey unfortunately the age of the children was not available to include on our selection criteria. The participants' level of depressed affect was assessed using a portion of the Center for Epidemiologic Studies Depression (CESD) scale, one of the most common screening tests for depression levels (Radloff 1977). The respondent's education was obtained from a self-report question, "What is the highest level of education that you completed/ are working on?" Descriptive statistics on depression ratings and all control variables are presented in Table 13.1.

We carried out the comparison between lone and partnered mothers in twin pairs by fitting a series of structural equation models using the robust weighted least squares (WLSMV) estimation option in the Mplus 7.11 program, used for model fitting (Muthén and Muthén 2013). WLSMV is a pairwise present estimation method, 
Table 13.1 Descriptive statistics for depression levels, age, education level, and number of children

\begin{tabular}{l|l}
\hline Indicator & Estimate \\
\hline CESD sum & \\
\hline$M$ & 7.44 \\
\hline$S D$ & 5.89 \\
\hline Range & $0-33$ \\
\hline 1st Quartile & 3 \\
\hline 3rd Quartile & 11 \\
\hline Age & \\
\hline$M$ & 33.14 \\
\hline SD & 7.62 \\
\hline Range & $20-47$ \\
\hline 1 st Quartile & 26 \\
\hline $3 r d$ Quartile & 40 \\
\hline Education Level & $\%$ \\
\hline Low level & $4.66 \%$ \\
\hline Mid level & $47.50 \%$ \\
\hline High level & $47.80 \%$ \\
\hline Number of Children & $\%$ \\
\hline 1 & $27.90 \%$ \\
\hline 2 & $50.00 \%$ \\
\hline 3 & $17.50 \%$ \\
\hline 4 or more & $4.42 \%$ \\
\hline &
\end{tabular}

and assumes data to be missing completely at random (Muthén and Muthén 2010). RMSEA was used as measure of model fit, with the cutoffs $0.01,0.05$, and 0.08 indicating excellent, good, and adequate fit, respectively (MacCallum et al. 1996).

We began by fitting univariate twin models, which partition the variance of an outcome into three components: additive genetic influences (A), shared environmental influences (C), and non-shared environmental influences (E). Genetic factors (A) represent the proportion of genetic material twins share that makes them similar to one another, and correlate at 1.0 for monozygotic (MZ) twins, who share $100 \%$ of their genes, and .5 for dizygotic (DZ) twins, who share on average $50 \%$ of their genes. Shared environmental factors (C) are the cumulative effect of environmental factors that make twins reared in the same family similar to one another, and correlate at 1.0 for both $\mathrm{MZ}$ and DZ twins, as they are assumed to fully share parts of their environment such as parental influences, socioeconomic status, or cultural background. The non-shared environmental factors $(\mathrm{E})$ do not correlate between twins, as these represent experiences that are not shared, and which contribute to their unique, within-pair variance.

Next, we fit a simple phenotypic model (Fig. 13.2), in which we regressed depression score on parenthood status to obtain an estimate of the observed effect of parenthood status on depression score (parameter bphen). This result represents the regression of parenthood status on depression score without statistically adjusting for the mediated effect of genetic and shared environmental selection confounds, 


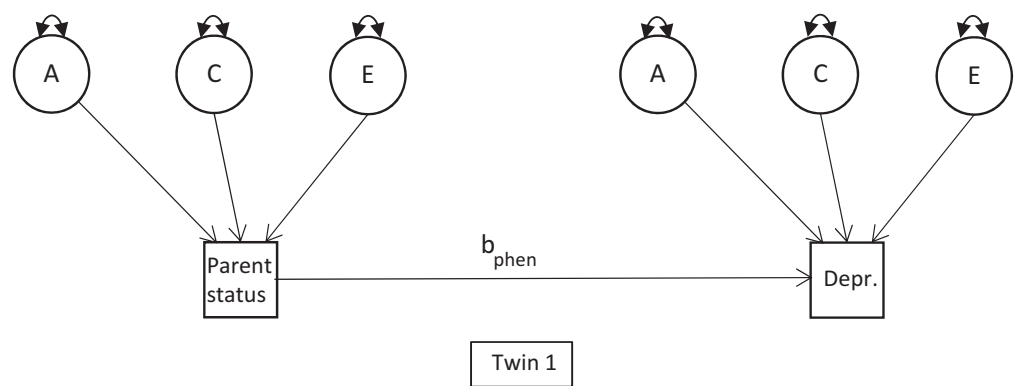

Fig. 13.2 Structural equation model representation of phenotypic model used in data analysis. This model is equivalent to a population-level regression

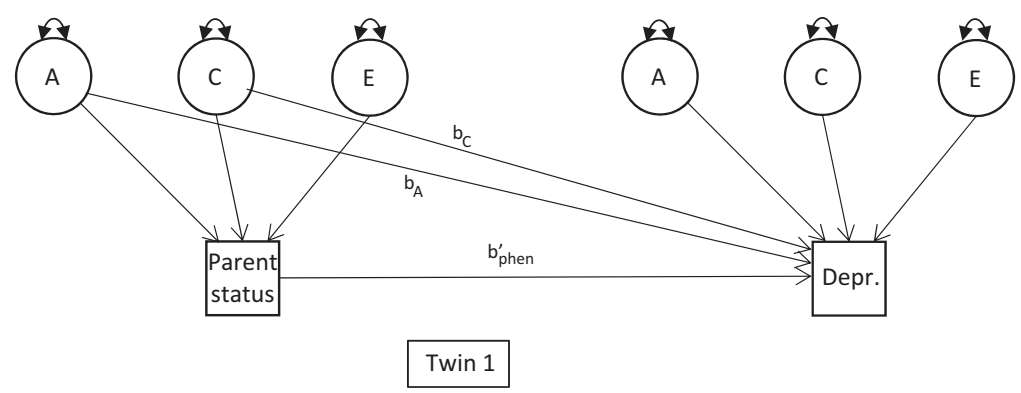

Fig. 13.3 Structural equation model representation of quasi-causal model used in data analysis. This model controls for genetic and shared-environmental confounds

and is equivalent to a population-level association. Finally, we fit a genetically informed phenotypic regression model (Fig. 13.3), in which the effect of parenthood status on depression score was estimated holding constant any genetic and shared environmental effects common to both parenthood status and depression level (Turkheimer and Harden 2013). In this model, we simultaneously regressed depression score on parenthood status (parameter b'phen - see Fig. 13.3) and on the $\mathrm{A}$ and $\mathrm{C}$ variance components of parenthood status.

If the $b^{\prime}$ phen parameter remains significantly different from zero after adjusting for the $\mathrm{A}$ and $\mathrm{C}$ regressions in the model, it can be interpreted as a quasi-causal effect of parenthood status on depression level. Such a result would support the causal hypothesis, suggesting that parenthood status has an effect on depression, above and beyond genetic and shared environmental influences that might explain the association. This means that in a pair of identical twins discordant for parenthood status (i.e. one twin is married and the other one is not) we will observe significantly different depression levels between the twins. Conversely, if the uncontrolled regression parameter bphen is significant, but $b^{\prime} p h e n$ is substantially reduced, even nonsignificant, the selection hypothesis would be supported. This means that the apparent effect of parenthood status on depression in the phenotypic model results at least in part from uncontrolled genetic and shared environmental factors. In other 
Table 13.2 Unstandardized parameter estimates for phenotypic and quasicausal models

\begin{tabular}{l|l|l}
\hline Estimate $(\mathrm{se})$ & Model 1: phenotypic & Model 2: Quasi-causal \\
\hline Regression coefficients & & \\
\hline Phenotypic model & & \\
\hline $\mathrm{b}_{\text {phen }}$ & $-0.15^{* * *}$ & - \\
\hline Biometric model & & \\
\hline $\mathrm{b}_{\mathrm{A}}$ & - & -0.956 \\
\hline $\mathrm{b}_{\mathrm{C}}$ & - & 0.80 \\
\hline $\mathrm{b}_{\text {phen }}^{\prime}$ & - & $-0.1 * * *$ \\
\hline Covariates & & \\
\hline Age & $-3.04^{* * *}$ & $-3.38^{* * *}$ \\
\hline Education & $0.23^{* * *}$ & $0.22^{* * *}$ \\
\hline Number of children & $0.11^{* * *}$ & $0.12^{* * *}$ \\
\hline Goodness of Fit & & \\
\hline RMSEA & 0.08 & 0.08
\end{tabular}

Note: Significance is denoted by asterisk: $<0.05(*),<0.01(* *),<0.001(* * *)$

$b_{\text {phen }}$ is the full phenotypic effect

$\mathrm{b}^{\prime}{ }_{\text {phen }}$ is the genetically informed phenotypic effect

$b_{\mathrm{A}}$ and $b_{\mathrm{C}}$ are the indirect effects of lone motherhood on depression

words, in a pair of identical twins in which one is a lone parent and one is not, we will observe the same depression levels in both twins. All the analyses used controls for number of children, education level, and age. Although using twins is a natural control for age, since twins are necessarily of the same age, we included age as an additional control variable to account for possible variations based on the age of the various pairs.

\section{Results}

Full results from the phenotypic and quasi-causal models are presented in Table 13.2. In the phenotypic model (Fig. 13.2) we regressed depression level onto a dichotomous variable representing motherhood status (i.e., partnered vs. lone), controlling for age, education level, and number of children. We found that the effect was significant $\left(\mathrm{b}_{\text {phen }}=-0.15 ; \mathrm{p}<0.001\right)$, which suggests a causal link between lone motherhood and depression in the general population. Importantly, when adding the genetic and shared environmental controls and running the quasi-causal model (Fig. 13.3), our results remained significant. We found evidence of a quasi-causal effect, such that lone mothers reported higher levels of depression than their partnered counterparts $\left(b^{\prime}{ }_{\text {phen }}=-0.1, \mathrm{p}<0.001\right)$. In other words, even in pairs of $\mathrm{MZ}$ twins, lone mothers are significantly more depressed than partnered mothers. The quasi-causal model included the same controls as the phenotypic model: age, education level, and number of children living with mother.

Our findings suggest that there is indeed a quasi-causal link between lone motherhood and depression, which remains even after we control for number of children, 
education level (which we used as a proxy for socioeconomic status), and age. Since these twin comparisons control for the genetic and shared environmental confounds that could impact this association, our result is closer to a causal interpretation of the relationship between lone motherhood and depression.

These findings are consistent with the literature on lone motherhood, and confirm that lone mothers are indeed at a higher risk for depression, even when considering other important variables such as number of children or education. However, twin research adds to the previous interpretations of these findings, by being able to eliminate entire classes of measurable and unmeasurable variables from the equation. It is not enough to know that lone motherhood is quasi-causally linked to depression, it is necessary to find the mechanisms through which this link functions, and twin research bring us one step closer to finding those mechanisms. It is clear from our analyses that the cause is not only genetic or environmental selection, and it is not only related to environmental factors such as socioeconomic status or number of children.

\section{Conclusion}

Sweden boasts very generous support for lone mothers, effective public policy measures, and significant public spending in support of these measures. It is conceivable that this would lead to a decrease in the negative consequences that lone motherhood seems to have on mental health and quality of life. We employed twin research to examine the association between lone motherhood and depression in a Swedish twin dataset. Twin research has significant advantages over traditional analysis methods, and is a useful tool in attempting to approach a causal interpretation of non-experimental data.

Our results show that even in Sweden, a country with exemplary policies aimed at helping lone mothers, lone mothers still report significantly higher levels of depression than partnered mothers. This result remains even when controlling for genetic and shared-environmental confounds, such as childhood environment and other upbringing influences. We chose to study Sweden due to its supportive policies towards lone mothers. These policies provide equal support for all lone mothers, thus reducing environmental variation. Given these conditions, we would expect a high degree of similarity between depression levels of partnered and lone mothers. Instead, we observed significant differences between the two groups.

Prior data explains the mental health consequences of lone motherhood in various ways, including financial strains and unmet child care necessities. We controlled for socioeconomic status and number of children in our analyses, and our results remained strong. Moreover, the policies in Sweden address these aspects and meet lone mothers' needs to a large extent. However, our results suggest that there might be a missing link, or an unexplained relationship between lone motherhood and depression. Policies that address the financial aspect of lone motherhood, or child care, while very useful, may not fully solve the problem. Our results suggest that simply offering lone mothers financial or child-care support may not fully correct the negative consequences that lone motherhood has on mental health. Lone mothers may 
need more social and psychological support in order to bridge the mental health gap, and increase their quality of life.

Despite the strengths of our chosen method of analysis, the fact that our data is cross-sectional limits our ability to draw true causal conclusions. While the genetically informed methodology we are using is the best way to draw quasi-causal conclusions based on the type of data we have available, it is conceivable that a variable that we did not control for, and which was not part of the genetic or shared environmental variance that we were able to account for in our models, might be impacting both parenthood status and depression. Future studies should seek to replicate our findings using a longitudinal design. Our data also did not allow for discussion of race or cultural differences. Thus, our findings generalize only to populations similar to our sample, which is primarily Caucasian and representative of a Northern European country. More exploration is needed before our conclusions can be generalized to other cultures.

Our study is the first investigation into lone motherhood using a genetically informed approach. Future research possibilities include exploring twin datasets in other countries, investigating the relationship between lone motherhood and other psychological indicators such as life satisfaction, self esteem, and self-efficacy, and adding moderators to analyses. Moreover, based on our results we suggest public policies offering more targeted mental health support for lone mothers, and more individualized support dependent on their life circumstances. Lone mothers seem to be missing more than the financial contribution that a partner would make, and thus any policies will hopefully broaden their scope to include other life aspects that lone mothers might be lacking, such as psychological support.

Acknowledgements This paper benefited from the support of the Swiss National Centre of Competence in Research LIVES - Overcoming Vulnerability: Life Course Perspectives, which is financed by the Swiss National Science Foundation (Grant number: 51NF40-160590).

\section{References}

Atkins, R. (2010). Self-efficacy and the promotion of health for depressed single mothers. Mental Health in Family Medicine, 7(3), 155-168.

Barnombudsmannen. (2010). Up to 18 - the facts on children and youth. Stockholm: Fritzes.

Beam, C. R., Horn, E. E., Hunt, S. K., Emery, R. E., Turkheimer, E., \& Martin, N. (2011). Revisiting the effect of marital support on depressive symptoms in mothers and fathers: A genetically informed study. Journal of Family Psychology, 25(3), 336-344.

Brady, D. (2006). Structural theory and relative poverty in rich Western democracies, 1969-2000. Research in Social Stratification and Mobility, 24(2), 153-175.

Brennenstuhl, S., Quesnel-Vallée, A., \& McDonough, P. (2012). Welfare regimes, population health and health inequalities: A research synthesis. Journal of Epidemiology and Community Health, 66(5), 397-409.

Brown, P. A. (2008). Poverty, public assistance and single mothers: A comparative look at Norway, Russia and the U.S. Journal of Comparative Social Work, 3(1), 1-24.

Brown, J. D., Harris, S. K., Woods, E. R., Buman, M. P., \& Cox, J. E. (2012). Longitudinal study of depressive symptoms and social support in adolescent mothers. Maternal and Child Health Journal, 16(4), 894-901. 
Burstrom, B., Whitehead, M., Clayton, S., Fritzell, S., Vannoni, F., \& Costa, G. (2010b). Health inequalities between lone and couple mothers and policy under different welfare regimes - The example of Italy, Sweden and Britain. Social Science \& Medicine, 70(6), 912-920. https://doi. org/10.1016/j.socscimed.2009.11.014.

Cairney, J., \& Wade, T. J. (2002). Single parent mothers and mental health care service use. Social Psychiatry and Psychiatric Epidemiology, 37(5), 236-242.

Cairney, J., Boyle, M., Offord, D. R., \& Racine, Y. (2003). Stress, social support and depression in single and married mothers. Social Psychiatry and Psychiatric Epidemiology, 38(8), 442-449.

Cairney, J., Boyle, M. H., Lipman, E. L., \& Racine, Y. (2004). Single mothers and the use of professionals for mental health care reasons. Social Science \& Medicine, 59(12), 2535-2546. https://doi.org/10.1016/j.socscimed.2004.03.035.

Carr, D., \& Springer, K. W. (2010). Advances in families and health research in the 21 st century. Journal of Marriage and Family, 72(3), 743-761.

Christopher, K. (2002). Caregiving, welfare states, and mothers' poverty. In R. Revier \& M. Tuominen (Eds.), Child care and inequality: Rethinking care work for children and youth. New York: Routledge.

Christopher, K., England, P., Smeeding, T. M., \& Phillips, K. R. (2002). The gender gap in poverty in modern nations: Single motherhood, The market, and the state. Sociological Perspectives, 45(3), 219-242.

Collings, S., Jenkin, G., Carter, K., \& Signal, L. (2014). Gender differences in the mental health of single parents: New Zealand evidence from a household panel survey. Social Psychiatry and Psychiatric Epidemiology, 49(5), 811-821.

Colton, T., Janzen, B., \& Laverty, W. (2015). Family structure, social capital, and mental health disparities among Canadian mothers. Public Health, 129(6), 639-647.

Cooper, C., Bebbington, P. E., Meltzer, H., Bhugra, D., Brugha, T., Jenkins, R., et al. (2008). Depression and common mental disorders in lone parents: Results of the 2000 National Psychiatric Morbidity Survey. Psychological Medicine, 38(3), 335-342.

Crosier, T., Butterworth, P., \& Rodgers, B. (2007). Mental health problems among single and partnered mothers. The role of financial hardship and social support. Social Psychiatry and Psychiatric Epidemiology, 42(1), 6-13.

Dinescu, D., Horn, E. E., Duncan, G., \& Turkheimer, E. (2015). Socioeconomic modifiers of genetic and environmental influences on body mass index in adult twins. Health Psychology, 35(2), 157-166. https://doi.org/10.1037/hea0000255.

Emery, R. E., Horn, E. E., \& Beam, C. R. (2012). Marriage and improved well-being: Using twins to parse the correlation, asking how marriage helps, and wondering why more people don't buy a bargain. In M. Garrison \& E. S. Scott (Eds.), Marriage at the crossroads: Law, policy, and the brave new world of twenty-first-century families (pp. 126-141). Cambridge: Cambridge University Press.

Evenson, R. J., \& Simon, R. W. (2005). Clarifying the relationship between parenthood and depression. Journal of Health and Social Behavior, 46(4), 341-358.

Fritzell, S. (2011). Social differentials in health among lone mothers in different policy contexts. Socialmedicinsk Tidskrift, 88(6), 575-633.

Fritzell, S., Vannoni, F., Whitehead, M., Burström, B., Costa, G., Clayton, S., \& Fritzell, J. (2012). Does non-employment contribute to the health disadvantage among lone mothers in Britain, Italy and Sweden? Synergy effects and the meaning of family policy. Health \& Place, 18(2), 199-208.

Haas, L. (1996). Family policy in Sweden. Journal of Family and Economic Issues, 17(1), 47-92.

Hewitt, B., Baxter, J., \& Western, M. (2006). Family, work and health: The impact of marriage, parenthood and employment on self-reported health of Australian men and women. Journal of Sociology, 42(1), 61-78.

Hope, S., Rodgers, B., \& Power, C. (1999). Marital status transitions and psychological distress: Longitudinal evidence from a national population sample. Psychological Medicine, 29(2), 381-389.

Horn, E. E., Xu, Y., Beam, C. R., Turkheimer, E., \& Emery, R. E. (2013). Accounting for the physical and mental health benefits of entry into marriage: A genetically informed study of selection and causation. Journal of Family Psychology, 27(1), 30-41. 
Horwitz, S. M., Briggs-Gowan, M. J., Storfer-Isser, A., \& Carter, A. S. (2007). Prevalence, correlates, and persistence of maternal depression. Journal of Women's Health, 16(5), 678-691. https://doi.org/10.1089/jwh.2006.0185.

Johnson, D. R., \& Wu, J. (2001). An empirical test of crisis, social selection, and role explanations of the relationship between marital disruption and psychological distress: A pooled time-series analysis of four-wave panel data. Journal of Marriage and Family, 64(1), 211-224.

Johnson, J. G., Cohen, P., Dohrenwend, B. P., Link, B. G., \& Brook, J. S. (1999). A longitudinal investigation of social causation and social selection processes involved in the association between socioeconomic status and psychiatric disorders. Journal of Abnormal Psychology, 108(3), 490-499.

Kaprio, J. (2015). Is the association between alcohol use and coronary artery disease causal? Evidence from a long-term twin study. The American Journal of Clinical Nutrition, 102(1), $1-2$.

Kenworthy, L. (1999). Do social-welfare policies reduce poverty? A cross-national assessment. Social Forces, 77(3), 1119-1139.

MacCallum, R. C., Browne, M. W., \& Sugawara, H. M. (1996). Power analysis and determination of sample size for covariance structure modeling. Psychological Methods, 1(2), 130-149.

Mastekaasa, A. (1991). Marriage and psychological well-being: Some evidence on selection into marriage. Journal of Marriage and the Family, 54(4), 901-911.

Misra, J., Budig, M., \& Moller, S. (2007a). Reconciliation policies and the effects of motherhood on employment, earnings and poverty. Journal of Comparative Policy Analysis: Research and Practice, 9(2), 135-155.

Misra, J., Moller, S., \& Budig, M. J. (2007b). Work family policies and poverty for partnered and single women in Europe and North America. Gender \& Society, 21(6), 804-827.

Misra, J., Moller, S., Strader, E., \& Wemlinger, E. (2012). Family policies, employment and poverty among partnered and single mothers. Research in Social Stratification and Mobility, 30(1), 113-128.

Muthén, L., \& Muthén, B. (2010). Mplus user's guide (6th ed.). Los Angeles: Muthén \& Muthén.

Muthén, B., \& Muthén, L. (2013). Mplus version 7.11 statistical analysis with latent variables: User's guide. Los Angeles, CA: Muthen \& Muthen.

Nordic Social Insurance Portal-Family Benefits. (n.d.). Retrieved August 29, 2014, from http:// www.nordsoc.org/en/Sweden/Family-benefits/

OECD. (n.d.). Gender wage gap. Retrieved September 13, 2015, from https://data.oecd.org/earnwage/gender-wage-gap.htm

Ozawa, M. N. (2004). Social welfare spending on family benefits in the United States and Sweden: A comparative study. Family Relations, 53(3), 301-309.

Pettit, B., \& Hook, J. (2005). The structure of women's employment in comparative perspective. Social Forces, 84(2), 779-801.

Radloff, L. S. (1977). The CES-D scale: A self-report depression scale for research in the general population. Applied Psychological Measurement, 1(3), 385-401.

Ritsher, J. E. B., Warner, V., Johnson, J. G., \& Dohrenwend, B. P. (2001). Inter-generational longitudinal study of social class and depression: A test of social causation and social selection models. The British Journal of Psychiatry, 178(40), 84-90.

Robinson, L. D., Magee, C. A., \& Caputi, P. (2014). Social support, work hours and health: A comparative study of sole and partnered Australian mothers. Women's Studies International Forum, 42, 19-27.

Simon, R. W. (2002). Revisiting the relationships among gender, marital status, and mental health. American Journal of Sociology, 107(4), 1065-1096.

Smeeding, T. M. (2005). Public policy, economic inequality, and poverty: The United States in comparative perspective. Social Science Quarterly, 86(s1), 955-983. https://doi. org/10.1111/j.0038-4941.2005.00331.x.

Sperlich, S., Arnhold-Kerri, S., \& Geyer, S. (2011a). Social living conditions and health among mothers in Germany: Findings from a population sample. Bundesgesundheitsblatt, Gesundheitsforschung, Gesundheitsschutz, 54(6), 735-744. 
Sperlich, S., Arnhold-Kerri, S., \& Geyer, S. (2011b). What accounts for depressive symptoms among mothers?: The impact of socioeconomic status, family structure and psychosocial stress. International Journal of Public Health, 56(4), 385-396.

Turkheimer, E., \& Harden, K. P. (2013). Behavior genetic research methods: Testing quasi-causal hypotheses using multivariate twin data. In H. T. Reis \& C. M. Judd (Eds.), Handbook of research methods in social and personality psychology (pp. 159-187). New York: Cambridge University Press.

Van de Velde, S., Bambra, C., Van der Bracht, K., Eikemo, T. A., \& Bracke, P. (2014). Keeping it in the family: the self-rated health of lone mothers in different European welfare regimes. Sociology of Health \& Illness, 36(8), 1220-1242.

Wang, J. L. (2004). The difference between single and married mothers in the 12-month prevalence of major depressive syndrome, associated factors and mental health service utilization. Social Psychiatry and Psychiatric Epidemiology, 39(1), 26-32.

Wells, M. B., \& Bergnehr, D. (2014). Families and family policies in Sweden. In M. Robila (Ed.), Handbook of family policies across the globe (pp. 91-107). New York: Springer New York.

Zabkiewicz, D. (2010). The mental health benefits of work: Do they apply to poor single mothers? Social Psychiatry and Psychiatric Epidemiology, 45(1), 77-87.

Diana Dinescu received her Ph.D. in Clinical Psychology from the University of Virginia (Charlottesville, VA, United States). Her research investigates the effect of marriage and family relationships on health outcomes using genetically informed methodology.

Megan Haney-Claus graduated from the college of William and Mary in 2016 with a double bachelor's degree in Marketing and Psychology. She currently works as Media Specialist for the marketing agency Merkle.

Eric Turkheimer is the Hugh Scott Hamilton Professor of Psychology at the University of Virginia. His current research includes detection of gene-environment interactions in twin studies of intelligence, development of statistical methods for the analysis of children of twins, and use of twins as controls in quasi-experimental designs to study the effects of parenting on adolescents' outcomes. In 2009 he has been awarded the James Shields Memorial Award for his research in Behavioral Genetics.

Robert E. Emery is Professor of Psychology and Director of the Center for Children, Families, and the Law at the University of Virginia. He has authored over 150 articles and several book on family relationships and children's mental health, including parental conflict, divorce, child custody, family violence and associated legal and policy issues.

Open Access This chapter is licensed under the terms of the Creative Commons Attribution 4.0 International License (http://creativecommons.org/licenses/by/4.0/), which permits use, sharing, adaptation, distribution and reproduction in any medium or format, as long as you give appropriate credit to the original author(s) and the source, provide a link to the Creative Commons license and indicate if changes were made.

The images or other third party material in this chapter are included in the chapter's Creative Commons license, unless indicated otherwise in a credit line to the material. If material is not included in the chapter's Creative Commons license and your intended use is not permitted by statutory regulation or exceeds the permitted use, you will need to obtain permission directly from the copyright holder.

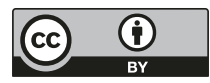

